\section{Necropsias de PERUANOS ILUSTRES}

Necropsies of illustrious peruvians

Manuel Zanutelli Rosas ${ }^{1}$

RESUMEN

El autor presenta los protocolos de necropsias de algunos personajes importantes de la vida política e intelectual del país que fueron asesinados. Así: los presidentes José Balta Montero (18141872), Manuel Pardo y Lavalle (1834-1878), Luis M. Sánchez Cerro (1889-1933); el empresario y periodista Francisco Graña Garland (1902-1947); y, el periodista y escritor Edwin Elmore Letts (18901925).

Palabras claves: Necropsia, asesinato, presidente, periodista.

Abstract

The author presents the necropsy protocols of some important figures of the political and intellectual life of the country who were killed. Thus: Presidents José Balta Montero (1814-1872), Manuel Pardo y Lavalle (1834-1878), Luis M. Sánchez Cerro (1889-1933); the businessman and journalist Francisco Graña Garland (1902-1947); and the journalist and writer Edwin Elmore Letts (1890-1925).

Keywords: Necropsy, murder, president, journalist.

a azarosa vida republicana de nuestro país no ha estado exenta de hecho violentos cometidos contra distinguidas personalidades de la vida política e intelectual.

A continuación, se revisará sucintamente los informes de necropsias de los presidentes que fueron asesinados y de dos connotados periodistas.

\section{José Balta Montero (1814-1872)}

Fue, sin lugar a dudas, un presidente progresista. Contribuyó a dar otra fisonomía a la ciudad de Lima.

1 Periodista, escritor, historiador.

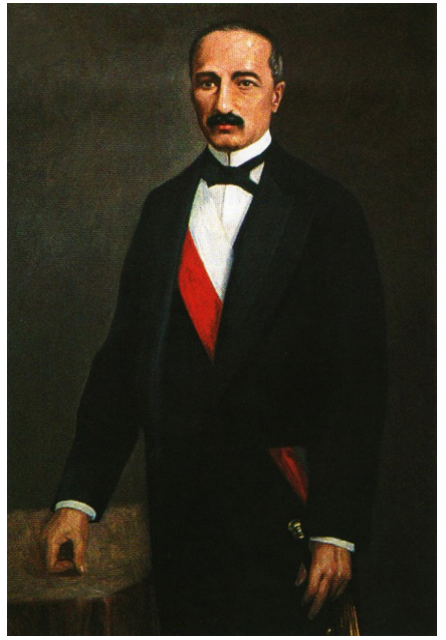

Don José Balta Montero

Dispuso que el contratista norteamericano Henry Meiggs derribara las murallas tal que hizo posible la expansión de la capital, tarea que se llevó a cabo entre 1868 y 1870. Ordenó al ingeniero Luis Sada, que trazara un plano de Lima y mediante decreto del 2 de agosto de 1869 se emprendió la construcción del Parque y Palacio de la Exposición, inaugurado después el $1^{\circ}$ de julio de 1872 .

Inició su carrera como alumno del colegio militar en 1835 a los 19 años y llegó al alto grado de coronel.

Su política de construcción de ferrocarriles la realizó sobre la base de empréstitos que tenían como garantía el guano de las islas. Fue asesinado el 26 de julio de 1872 en el cuartel 
de San Francisco por los coroneles hermanos Gutiérrez, quienes se habían amotinado al conocerse como ganador de las elecciones presidenciales al civil Manuel Pardo.

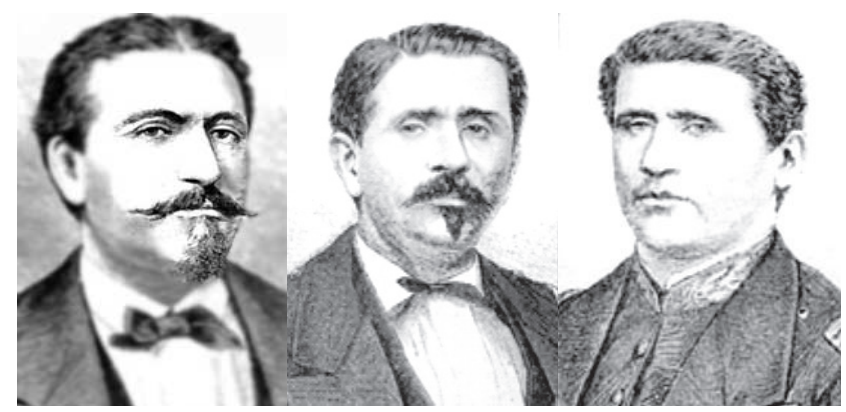

De izquierda a derecha: Tomás, Silvestre y Marceliano Gutiérrez.

El diario El Nacional narró lo siguiente:

Publicamos en seguida las conclusiones del informe de los médicos de policía encargados por la autoridad de reconocer el cadáver del expresidente Balta.

Que el cadáver tiene 11 heridas, que presentan caracteres anatómicos de origen contuso, y que han dado margen a grandes desórdenes movidos (sic) por interesar varios órganos y regiones del cuerpo.

Que atendiendo a la formal situación, dirección y más que todo a la naturaleza de las alteraciones anatomo patológicas, que presentan las mencionadas heridas: diez de estas son practicadas con armas de fuego, y la otra es resultado de la acción de un instrumento punzante y cortante.

Que la disposición anatómica de las heridas manifiesta evidentemente que el proyectil ha sido descargado por mano extraña y a boca de jarro.

Que presentan las heridas de armas de fuego dos diámetros diversos: dichas armas, o son de una misma clase, pero de distinto calibre, o bien de diferente orden.

Que ocasionando el proyectil profundas lesiones patológicas en los órganos más importantes para la vida del hombre como son los pulmones, hígado y estómago, a la vez que hemorragias activas y fracturas irregulares y múltiples en los huesos principales de la cara, clavicula izquierda, húmero derecho, del antebrazo izquierdo $y$ costillas; la muerte ha debido ser la consecuencia fatal inmediata.

$Y$ que se adjuntan al presente certificado dos proyectiles extraídos al cadáver durante la operación de embalsamamiento por los doctores José Julián Bravo, José María Macedo, Francisco Rosas, Leonardo Villar, Rafael Grau, Manuel Adolfo Olaechea, Ezequiel Miranda; y para que conste firman el presente.

Lima, julio 29 de 1872. Manuel Olaechea, Tomás Salazar.

\section{Manuel Pardo y Lavalle (1834-1878)}

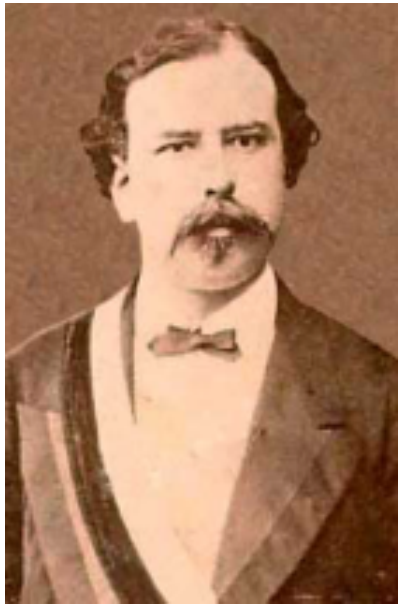

Manuel Pardo y Lavalle

El 16 de noviembre de 1878, el presidente del Senado Manuel Pardo y Lavalle, hijo de Felipe Pardo y Aliaga y de Petronila Lavalle, fue 
asesinado por el sargento Melchor Montoya, integrante del batallón Pichincha, cuando había ingresado al local del Parlamento.

Don Manuel González Prada en su libro Figuras y figurones, dijo que en Lima "se convino en asegurar que algunas personas honorables habían cargado el rifle de Montoya".

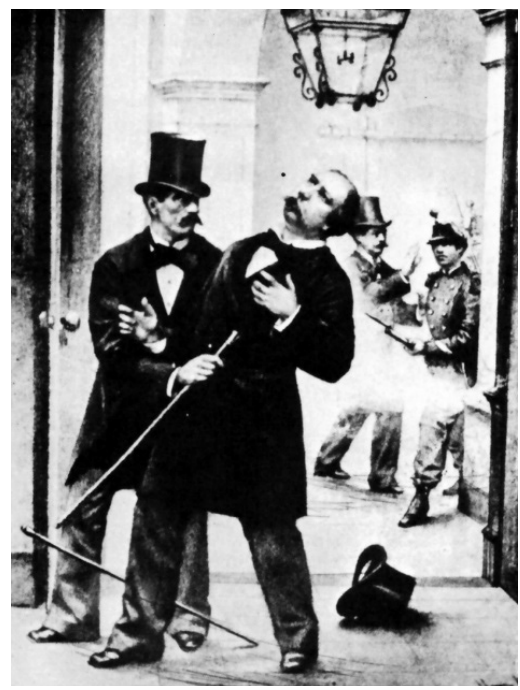

El motivo: se estaba discutiendo una ley que impediría el ascenso de las clases a oficiales. Fue presidente de la República de 1872 a 1876. Manuel Pardo había nacido en Lima el 9 de agosto en 1834, estudió en Chile y posteriormente en el colegio de Guadalupe, y finalmente en el Convictorio de San Carlos, que dirigía Bartolomé Herrera. Casado con Mariana Barreda Osma, su hijo José llegaría como él a la primera magistratura del país.

Melchor Montoya, el sicario, solo fue la mano ejecutora.

El diario El Comercio del 16 de noviembre de 1878, en su edición de la tarde, se expresó en los siguientes términos:

Los señores doctores Mariano Macedo, Vélez, Villar, Olaechea, Sánchez Concha y Fernández embalsamaron el cadáver del señor Pardo. La operación comenzó a las 5 de la tarde y terminó a las 9 menos un cuarto de la noche. Los líquidos necesarios fueron preparados por el farmacéutico señor Grec.

Hecha la autopsia se ha visto que el proyectil penetró por la parte posterior del tronco, casi al nivel de la escápula (paletilla) fracturando las costillas $4^{a}$ y $5^{a}$ en su parte posterior, y $2^{a} y$ $3^{a}$, en la anterior. El pulmón izquierdo estaba atravesado. El corazón había sido tocado. En la cavidad del pulmón interesado se encontró una cantidad de dos litros aproximadamente de sangre. El embalsamamien to fue hecho por un sistema mixto.

Después del examen hecho para el embalsamamiento, se observó lo siguiente: todos los órganos internos se encontraban en el más perfecto desarrollo, sin que se notara en los pulmones nada que manifestara haber estado enfermo con tubérculos, como se creyó alguna vez y por cuya razón tuvo que ir al clima de Jauja.

El hígado ligeramente congestionado, presentaba en la sustancia parenquimatosa, ligeros quistes. El corazón y las demás vísceras en completa sanidad, de tal modo que el señor Pardo ha podido vivir muchos años, si la mano de un criminal no hubiera cortado el hilo de tan preciosa existencia.

Los órganos interesados por el plomo homicida han sido la paletilla izquierda, (escápula), las costillas $4^{a} 2^{a}$ y $1^{a}$ considerando la marcha del proyectil de atrás hacia adelante y de abajo arriba; el lóbulo superior del pulmón izquierdo y algunos vacíos de poca importancia. La lesión del pulmón, que dio lugar a una abundantísima hemorragia, fue la causa inmediata de la muerte.

Uno de los médicos que practicaron la autopsia, nos dice que si el proyectil con que fue herido el 
señor Pardo no hubiera sido de rifle Comblay, tal vez se habría podido salvar la vida.

\section{Luis M. SÁnchez Cerro (1889-1933)}

Luis Alayza y Paz Soldán, quien lo conoció, decía que era pequeño y oscuro como una pastilla de Evans. Había nacido en San Miguel de Piura el 12 de agosto de 1889 pero estaba destinado a vivir poco. Asumió la conducción del país el 8 de diciembre de 1931 a los 44 años y fue asesinado por un fanático en el hipódromo de Santa Beatriz, el 30 de abril de 1933.

El mandatario había sido un personaje popular. En el ejército se le conocía como El negro; el pueblo, que lo apoyó en las elecciones y le dio 152000 votos lo llamaba cariñosamente El collota, por faltarle el dedo índice de la mano derecha que perdió el 4 de febrero de 1914.

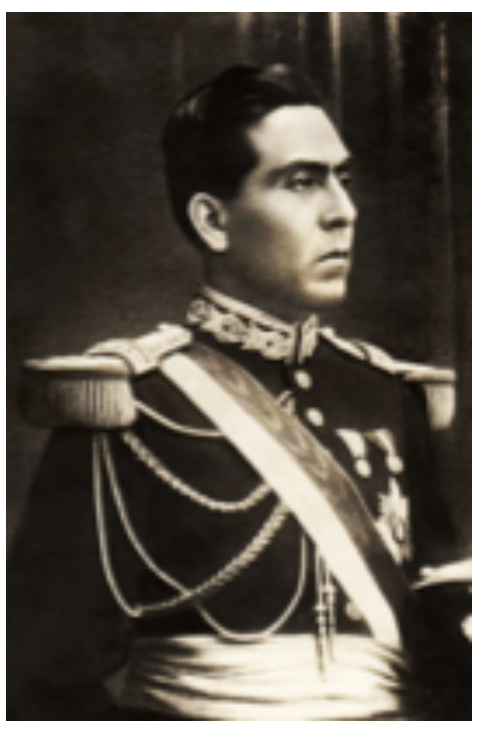

Luis M. Sánchez Cerro

Después del desfile de movilizables, realizado en medio de un gran fervor patriótico, el presidente y su comitiva pasaron a un salón. Media hora después, a la una y quince de la tarde, se retiró en el auto Hispano Suiza descubierto que tenía asignado, en el que acostumbraba desplazarse $y$, para evitar que alguien fuese atropellado, dio orden de que avanzara lentamente.

En el asiento delantero iba el jefe de la Casa Militar coronel Antonio Rodríguez y el edecán mayor Eleazar Atencio. Sánchez Cerro, acomodado en el asiento de atrás, estaba acompañado por José Matías Manzanilla, ministro de Relaciones Exteriores y, a la vez, presidente del Consejo de Ministros. Los seguía un auto con cuatro oficiales: un comandante, un mayor y dos capitanes.

El parte de la Octava Comisaria dice: "Que de la muchedumbre estacionada a ambos costados de la salida del hipódromo, surgió un individuo en actitud de aplaudir, como lo hacía la mayoría del público". Los soldados de la Guardia Republicana ante esta actitud, "lo dejaron surgir". Corrió hacia la parte posterior del auto presidencial, se agarró a él con la mano izquierda y con la derecha comenzó a disparar. De nada sirvió su custodia porque resultó insólitamente inútil. Quien había disparado era un peruano del Perú profundo, “bajo, mestizo, vestido de azul, mal trajeado, sin chaleco y una camisa a rayas" le fue fácil escurrirse entre policías y detectives y matarlo. Conducido al Hospital Italiano, situado en la cuadra once de la avenida Abancay, fue asistido por los doctores Juan Luis Raffo, Ernesto Delgado Gutiérrez y Teófilo Rocha. Después se unieron a ellos los también médicos Carlos Monge, Juan José Mostajo y Carlos Brignardello.

A pesar de todos los esfuerzos realizados, el general Sánchez Cerro falleció. A su lado estuvo sor Eugenia hasta el instante final de su deceso. Ese mismo día el Congreso Constituyente nombró presidente de la República al general Óscar R. Benavides. 
El protocolo de necropsia decía lo siguiente: "Que esta muerte violenta fue debida a dos heridas por arma de fuego, perforante una del tórax y la otra penetrante de las cavidades torácica y abdominal". Suscribieron el documento los doctores José Darío Torres, Guillermo Fernández Dávila, Ángel Parodi Vaccaro, Fernando Wieland y José María Herrera.
Brigada presidencial a cargo de un teniente al mando de 33 hombres; b) Inspección general de Investigación y Vigilancia, "con un efectivo de 130 hombres"; y c) Sección de Orden Público, "a órdenes del señor prefecto del departamento, que tiene 25 hombres a disposición de don Damián Mústiga".

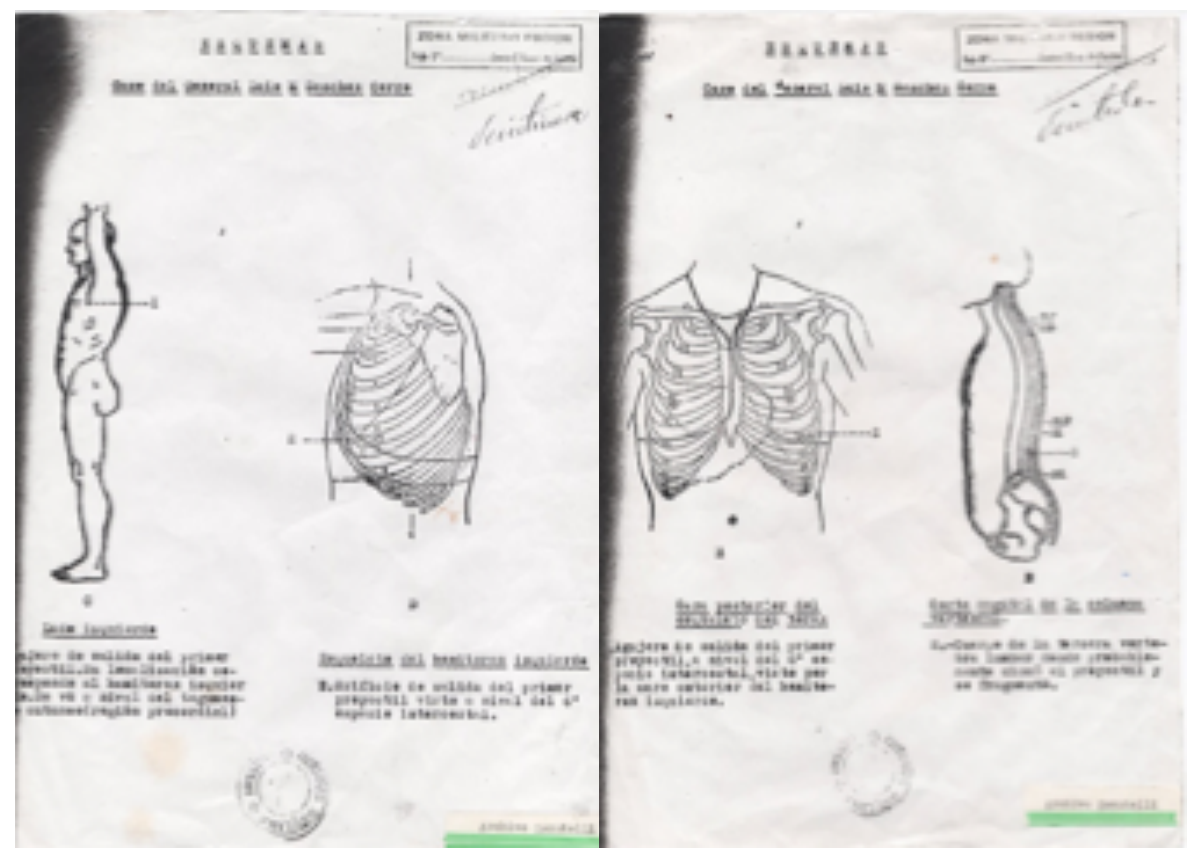

Parte del protocolo de autopsia de Lis M. Sánchez Cerro.

Luego de ser embalsamado por el doctor Fernández Dávila, se hicieron cargo de él los miembros de la Casa Militar. "El corazón -dice el mismo documento-, fue colocado en un frasco especial y entregado al mayor Solari".

De la instrucción que se abrióa propósito de este suceso que conmocionó al país, el mayor juez instructor de la Corte Marcial, en el documento que dirigió al coronel presidente de ese organismo, le expresó que había habido "delito de negligencia". Estaba comprobado que para el resguardo del jefe de Estado se disponía de: a)
Y, expresó algo que es históricamente cierto: "la muerte de este criminal oscurece el sumario".

El desconcierto fue tan grande que los guardias republicanos y los edecanes, todos ellos inseguros, sin dominio de sus nervios, profesionalmente incapaces, empezaron a disparar a tontas y a locas, de manera irresponsable. El asesino trató de huir, pero fue atravesado por la bayoneta del soldado Teodoro Rodríguez, miembro de la Guardia Republicana, quien murió de un balazo en la cabeza, disparado por sus propios 


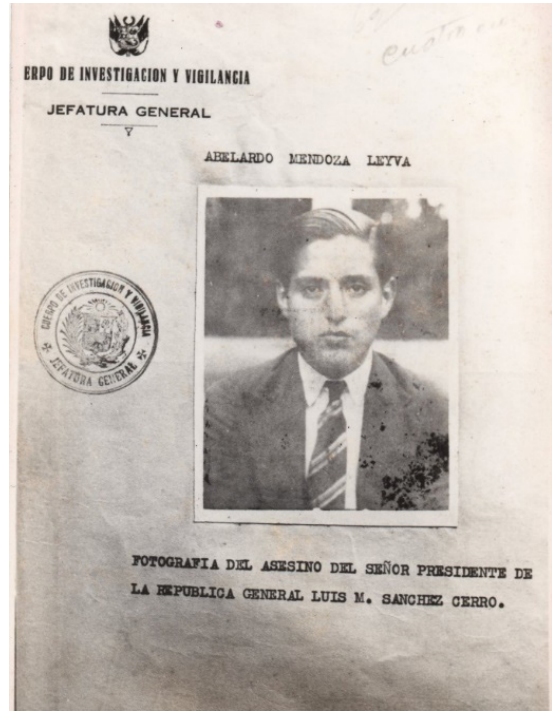

Fotografía del asesino de Luis M. Sánchez Cerro.

compañeros. Se estableció que al mandatario trece proyectiles le causaron 20 heridas. Así quedó, convenientemente, difunto.

A nadie se le ocurrió que el atacante debía ser apresado con vida para ser interrogado. Fueron heridos un alférez, un sargento, y tres soldados, quienes tuvieron que ser evacuados al hospital militar de San Bartolomé.

La policía y los periódicos dieron a conocer que el asesino se llamaba Abelardo Mendoza Leyva. Según el informe del Cuerpo de Investigación y Vigilancia, era de Cerro de Pasco, radicó en Lima desde niño, vivió en la calle de Malambo en la casa de Antonio Martino, como doméstico, y en la misma condición, durante tres años, a órdenes de José Balestra.

A los 14 años de edad fue mozo en el bar Piñita, situado en la Calle del Serrano (octava cuadra del jirón Camaná y La Colmena), pero sus robos de dinero le hicieron perder el empleo y fue así como se dirigió a La Punta donde encontró colocación en el hotel Ribera Palace.
De nuevo en Lima, la dueña de una fonda de la calle Huáscar número 281, del barrio de Surquillo, al notar que a diferencia de los demás parroquianos pedía un solo plato, lo hizo llamar con uno de sus mozos. Y confesó que estaba sin trabajo. Como tenía vacante el puesto de cocinero, la señora se lo ofreció.

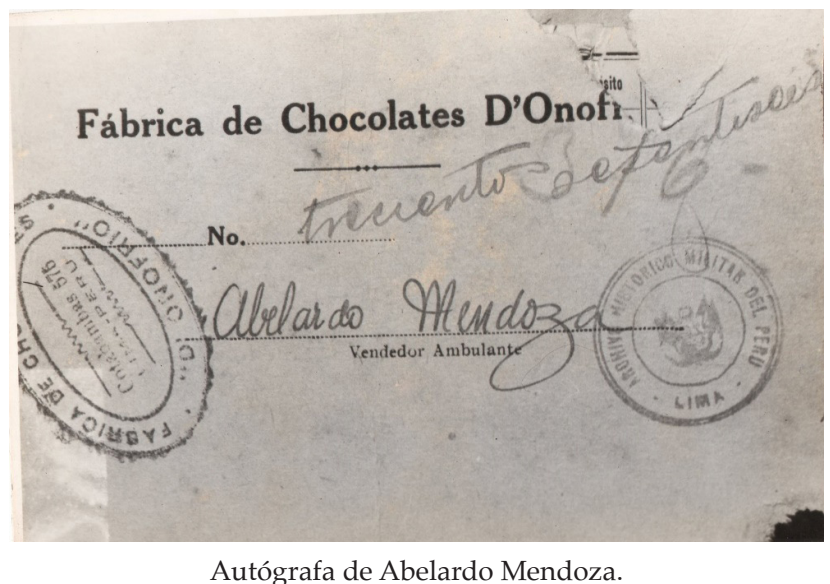

Desde el 24 de abril de 1933 había sido vendedor ambulante de la empresa D) Onofrio, en su afán de mejorar su situación. Vivía en Casma 240, una transversal de la $2^{\text {a }}$ cuadra del jirón Trujillo en el Rímac.

El arma utilizada por el asesino no pudo ser hallada en el lugar del crimen. Fue recogida por el ciudadano Ángel Millán Ramos, quien de esa manera se complicó la vida. La encontró en el suelo. Era uno de los espectadores cercanos al auto del presidente, la guardó en uno de sus bolsillos y se retiró a su domicilio. Al día siguiente viajó a Huancayo, mientras en la Brigada de Investigaciones se preguntaban dónde estaba el "cuerpo del delito".

Elrevólver nolohubiesen encontradonunca sila conviviente de Millán, de nombre Eva Sánchez Rivero, no comunicaba a la policía lo que su pareja le confiara. Se trataba de una pistola Browing número 352872, calibre 7.65, que 
sólo así pudo ser remitida a Lima. Estuvieron detenidas 19 personas, unas sospechosas de complicidad y otras en condición de encubridoras. Sufrieron mucho porque fueron sometidas a largos interrogatorios. A ninguna se le encontró culpabilidad y tuvieron que ser dejadas libres.

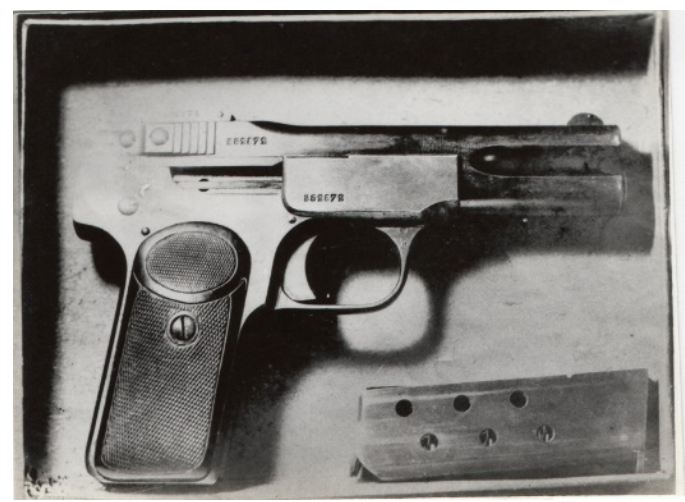

Pistola Browning con que fue asesinado Luis M. Sánchez Cerro.

\section{Francisco Graña Garland (1902-1947)}

Durante el cogobierno de José Luis Bustamante y Rivero con el Partido Aprista (1945-1948) se trató de otorgarle a la International Petroleum Company "una concesión perpetua de derecho de perforación petrolera en el desierto norteño de Sechura", (Alfonso Quiroz en su libro La corrupción en el Perú en el Perú, 2013).

Graña, mediante el diario La Prensa se opuso firmemente con argumentos que le ganaron seguidores. No imaginó, no pudo imaginar, no obstante su experiencia política, que había firmado su sentencia de muerte.

En la noche del 7 de enero de 1947 cuando salía del laboratorio Sanitas fue derrumbado a balazos y, aunque lo auxilió y lo condujo al Hospital Italiano el personal de la empresa, no se pudo salvarle la vida.
El doctor Enrique Camprubí declaró a los periódicos que él y el doctor Carlos Melzi comprobaron que Graña había dejado de existir minutos antes, luego de llegar al nosocomio, y que el cadáver presentaba "cinco heridas de bala, todas en el lado izquierdo: una en el cuello, una en el hombro, dos en el codo y la restante en el flanco izquierdo".

Sus atacantes huyeron en un automóvil marca Buick. Sin embargo, la policía se mostró extrañamente lenta en la investigación, y hubo que contratar, en desmedro de la imagen de la policía peruana, a un investigador extranjero.

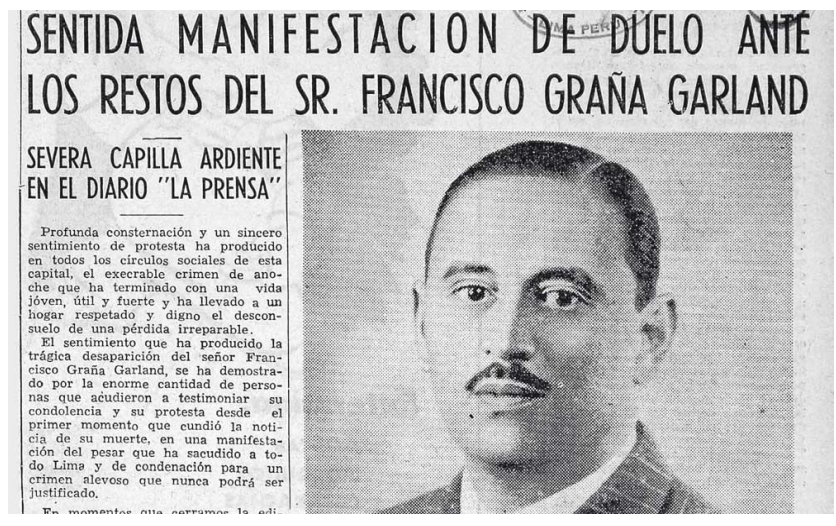

Fueron detenidos Manuel López Obeso, Alfredo Tello, y Héctor Pretell. El alevoso asesinato se transformó en un escándalo político. Del autor intelectual no se sabía nada. Leamos el protocolo de autopsia, en realidad necropsia, que es el siguiente:

Morgue de Policía de Lima. Autopsia número 11,589. Fecha: 7 de enero de 1947. Edad: 47 años.

Juez: Cesáreo Vidalón.

A las 8 pm ingresó al Hospital Italiano el cadáver del adulto Francisco Graña Garland, de 47 años de edad, de sexo masculino, de raza blanca, nacido en Lima, de profesión comerciante y de estado casado.

Remitido por la Comisaría de Pueblo Libre para investigar la causa de su muerte; habiéndose 
practicado la autopsia el día 7 a las 12 pm., en presencia del señor Juez Instructor.

Datos referentes a la fecha y hecho de la muerte: fue victimado con arma de fuego, según el parte de policía.

Estatura: 1.80.

Constitución: buena.

Panículo adiposo abundante.

Masas musculares: bien desarrolladas.

Prendas de ropa que le cubrían: un pantalón beige manchado de sangre en la parte anterior $y$ posterior, un calzoncillo blanco, un par de medias blancas, un par de zapatos y dos sábanas manchadas de sangre.

Objetos encontrados en los bolsillos: ninguno.

Signos cadavéricos: rigidez escasa.

Manchas cadavéricas: livideces en la parte posterior.

Estado de los esfinteres: relajados.

Fenómenos oculares: opacidad corneal.

Grado de putrefacción nulo:

Fauna cadavérica: no hay.

Data de la muerte: 6 horas.

Piel trigueña.

Pelo: negro, lacio, escaso.

Cejas: negras.

Bigote: negro, recortado.

Barba: afeitada.

Ojos: parduzcos.

Párpados: normales.

Nariz: normal.

Fosas nasales: normales.

Labios: delgados.

Dientes: primer molar inferior izquierdo platinado; los demás completos y bien cuidados.

Boca: normal.

Lengua: normal.

Ojos: livideces.

Conducto auditivo: normal.

Cerebro: no se abrió por haberlo ordenado el Juez

Instructor.

Pulmones: izquierdo manchado de sangre.

Páncreas: hay pero pálido, exangüe.
Apéndice: extirpado quirúrgicamente.

Vesícula biliar: normal.

Riñones: normales exangües al corte.

Vejiga: vacua.

Canal raquídeo: no se abrió.

Órganos genitales: normales.

Causa de la muerte: Heridas por arma de fuego de pequeño calibre, cañón corto, penetrante el cuello, tórax y abdomen, inferidos por mano ajena.

Conclusiones:

$1^{a}$ Que don Francisco Graña Garland, de 47 años de edad, falleció violentamente.

$2^{a}$ La violencia de su muerte fue debida a heridas por arma de fuego de pequeño calibre, penetrante del cuello, abdomen y tórax.

$3^{a}$ Pero que las heridas descritas en $1^{\circ}$ y $2^{\circ}$, en primer y $2^{\circ}$ lugar fueron las que le causaron la muerte.

$4^{\circ}$ Que la herida del cuello determinó la ruptura del paquete vascular nervioso del lado izquierdo, con gran hemorragia externa e interna.

$5^{\circ}$ Que la herida descrita en $2^{\circ}$ lugar, es de dirección ascendente y el proyectil comprometió el bazo, el lóbulo izquierdo del hígado, diafragma, pericardio, ventrículo derecho el que perfora de abajo hacia arriba, entra en la cavidad ventricular y vuelve a perforar el corazón, en la pared anterior de dicho ventrículo, para exteriorizarse a nivel del espacio intercostal donde se encuentra. $6^{a}$ Que estas heridas eran de naturaleza mortal inmediata y que por la ubicación y características de sus orificios de entrada por la dirección seguida por los proyectiles y su ubicación al término de su trayectoria, corresponden a heridas inferidas por mano ajena, y a una distancia mayor de 50 centímetros;

$7^{\circ}$ Que en el acto de la autopsia los proyectiles fueron entregados al señor Juez Instructor de turno, doctor Cesáreo Vidalón, que presenció la autopsia.

Lima, 7 de enero de 1947.

Firmado, director. Firma ilegible. 
Con relación a la firma, el diario El Comercio dijo que la autopsia había sido efectuada por el doctor José Darío Torres, director de la Morgue. Era un prestigioso médico legista especializado en otorrinolaringología, ex alumno de San Fernando, quien inició sus estudios en 1914. En 1930 asumió la dirección de la Morgue. Fue docente en la Universidad de San Marcos y falleció el 4 de junio de 1959, "víctima de una afección gástrica súbita", según el diario El Comercio del 5 de junio de 1959. El mismo diario dijo que "pasó los 28 últimos años de su vida prácticamente entre los cadáveres de la morgue, donde desempeñaba el cargo de director". Era considerado el decano de los médicos legistas.

\section{EdWIN ElMORE LeTTS (1890-1925)}

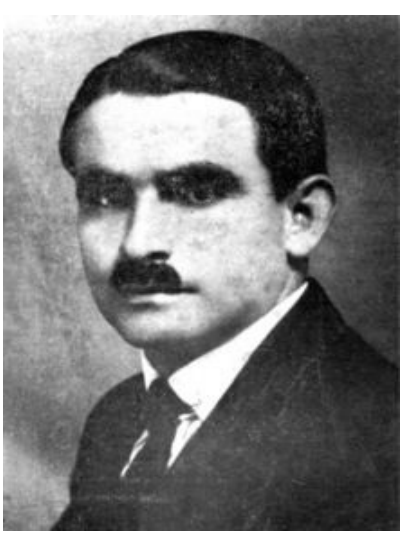

Edwin Elmore Letts

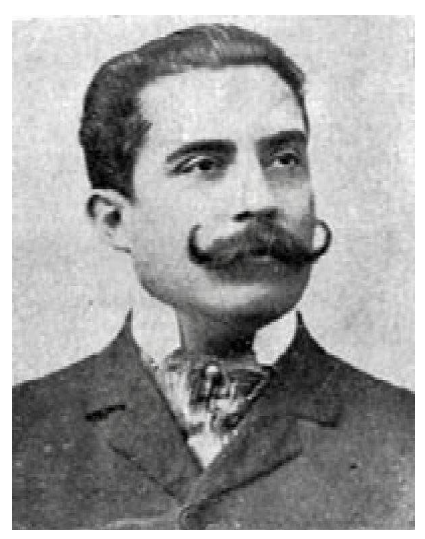

José Santos Chocano
El periodista y escritor Edwin Elmore Letts era hijo del ingeniero Teodoro Elmore, quien el 7 de junio de 1880, en Arica, recibió la orden del coronel Francisco Bolognesi de hacer volar el Morro legendario con defensores e invasores. El cableado eléctrico de baterías no funcionó y los chilenos avanzaron por el Morro y la ciudad sin temor alguno.

Le cargaron la culpa a Elmore y hubo razones para que fuese así. Mariano Felipe Paz Soldán, comentaba: "Días antes de que el general Prado se retirase a Lima [26 de noviembre] nombró una comisión compuesta del coronel de artillería Arnaldo Panizo, el ingeniero Teobaldo Eléspuru y del mayor Ugarteche para llevar a cabo la defensa de la plaza por su retaguardia o sea por tierra". Soldados chilenos a caballo del escuadrón Carabineros de Yungay, sorprendieron al ingeniero Elmore y al teniente Pedro Ureta en Chacalluta. Fue hecho prisionero el 29 de mayo de 1880.

Esa es la historia del ingeniero Teodoro Elmore, controvertida y dudosa, pero nunca comprobada. De esa manera le dejó a su hijo un legado de muerte.

Dos fueron los consejos de guerra en los que la guarnición, representada por sus más altos jefes a la cabeza del coronel Bolognesi, decidió no rendir las armas, luchar hasta quemar el último cartucho. El primer consejo se efectuó el 28 de mayo de 1880 y el segundo el 5 de junio. En la colección documental de Pascual Ahumada Moreno, Guerra del Pacífico (8 tomos), figura una carta del capitán Manuel $R$. Barahona que dice: “Un ingeniero Elmore era el que había dirigido el trabajo de minas con que están rodeadas todas las trincheras y parapetos. Por éste supimos todo lo que necesitábamos para hacernos cargo de la manera cómo estaban defendidos los fuertes. Él eligió entre ser fusilado y hablar sin mentir". ¿Por qué se expresó así? El coronel Pedro Lagos en Arica dio la orden de fusilarlo si se negaba a colaborar con información sobre los reductos; pero el ingeniero se negó amparándose en el Derecho Internacional. Pronto se convenció que sus palabras carecían de valor ante los vándalos chilenos, y se comportó como un hombre de poco carácter y demostró al final que era un flojón, porque no asumió una actitud firme cuando el coronel Lagos le exigió que fuese al campo peruano y le trasmitiera al 
coronel Bolognesi las exigencias de rendición del jefe chileno. Bolognesi se negó a recibirlo. No reconoció su carácter de parlamentario precisamente por ser peruano y lo despidió visiblemente indignado.

En la página 214 de su estudio sobre Arica, escribe Gerardo Vargas:

“Cuando Bolognesi intentó hacer explotar personalmente las minas de Elmore, exclamó: traición, por no haber dado fuego ninguna de ellas". "También ingresó por Azapa en la tarde del 6, sin ser advertido, el ingeniero Elmore, enviado por Lagos para inducir a Bolognesi a que aceptara la capitulación propuesta el día anterior".

Tan grave hecho histórico tendría muy lamentables resonancias futuras. Lo utilizó, malamente, el poeta José Santos Chocano contra un hijo de Elmore, el joven intelectual Edwin Elmore, en una polémica de 1925. Chocano admirador de las tiranías organizadoras lamentaba que en el Perú no hubiese habido un gobierno como el de Juan Manuel de Rosas en Argentina o de Diego Portales en Chile. Elmore no estaba de acuerdo con esta forma de pensar.

A pesar de que hubo conversaciones e informes entre los sobrevivientes, que ponían a salvo su patriotismo y su comportamiento cívico y militar, Chocano se atrevió a llamarlo por teléfono y preguntarle:

- ¿Hablo con Edwin Elmore?

- Sí.

- ¿Con el hijo de Teodoro Elmore?

- Síseñor.

- ¡Ah! el hijo del traidor de Arica.

Debemos recordar lo que escribió Gerardo Vargas en La batalla de Arica: 7 de junio de 1880 (publicada en 1921):
"Desde el primer día en que el coronel Bolognesi se hizo cargo de la defensa de la plaza, se dedicó a mejorar la defensa de ésta; tuvo por colaboradores entusiastas en esta obra, al ingeniero Teodoro Elmore".

Entre Chocano y Elmore estaba anidado el odio y el destino les tenía un presente trágico, la ofrenda o regalo que nadie desea.

Elmore, impetuoso (y quizá arrebatado) no quiso acudir al código del marqués de Cabriñana, tan presente nombrado por los que no querían exponerse a nada. Su mejor código de honor eran sus puños. Chocano, un hombre maduro en el lindero de la vejez, no aflojó. Limeño con mucha calle, se defendió como pudo, y sabiendo que tenía todas las de perder, terminó el problema a balazos.

El diario El Comercio del domingo $1^{\circ}$ de noviembre de1925, informólargamente sobreel ataque de Chocano a Edwin Elmore. "Tenemos el sentimiento de anunciar a nuestros lectores que el hall principal El Comercio fue teatro ayer de una lamentable y sangrienta escena, como consecuencia de la cual se halla gravemente herido el señor Edwin Elmore".

Ese día, "minutos antes de las cinco de la tarde", se encontraron inesperadamente en el citado periódico, y cómo entre ambos se había originado el diálogo al que se ha hecho referencia, se produjo la violencia.

“El señor Elmore sujetaba de la solapa, con la mano izquierda, al señor Chocano, mientras con la derecha le golpeaba el rostro". El poeta "logró desasirse de su contendor", extrajo un revólver de uno de los bolsillos y disparó. Elmore cayó y Chocano fue desarmado. El oficial jefe del cuartel $2^{\circ}$ lo condujo a la comisaría. El revólver era un Smith Wesson calibre 38. El herido fue internado en el 
Hospital Italiano y lo atendieron los doctores Guillermo Gastañeta y José Bazzochi; después se incorporaron otros profesionales, pero falleció.

La necropsia fue realizada por los doctores Américo Accinelli y Adrián Pastor. El informe que suscribieron ambos galenos detalló:

"que las seis perforaciones del intestino estaban cerradas; que había en la vejiga una ligera herida, que todo el vientre presentaba huellas de peritonitis generalizada, y que el proyectil se encontraba incrustado en uno de los huesos de la pelvis (ilíaco) presentando los demás órganos las huellas peculiares a los procesos tóxicos".

En junio de 1926 el Tribunal Correccional condenó a Chocano a tres años de cárcel, pero no obstante ser una sentencia benigna ni siquiera la cumplió porque el Congreso cortó el juicio el 10 de abril de 1927.

El tiempo que estuvo preso en el Hospital Militar, no obstante su condición de civil, lo utilizó para desde allí editar el periódico La Hoguera y así herir y burlarse de todo el mundo. Colaboró con él la periodista Ángela Ramos. Su abogado Carlos Dulanto, no estuvo de acuerdo con el fallo y, como recuerda Luis Alberto Sánchez, interpuso un recurso de nulidad. Causó indignación que el Congreso ordenase cortar el juicio y de esa manera el reo abandonó su cárcel dorada desde el 10 de abril de 1927.

Su presencia en el país era insoportable. Ya no le quedaban amigos ni protectores. Leguía, en su calidad de presidente ya no atendía sus llamadas. En cambio, lo odiaban muchísimos peruanos y lo calificaban de indigno. En octubre de 1928 abandonó el país, pero lo abandonó como un réprobo y la gente fue olvidándolo.

Durante su estancia en Chile, sin el apoyo oficial de ningún gobierno, su vida se transformó en un infierno. La miseria lo agolletó. Fue asesinado por Martín Bruce Padilla. Este lo mató a cuchilladas el 13 de diciembre de 1934 en un tranvía. Bruce era un enfermo mental con quien Chocano equivocadamente había iniciado la búsqueda de un presunto tesoro en una calle de Santiago.

Vivía el poeta en una casa pequeña de la calle Eduardo Llanos. Su pobreza era extremada, según la comprobación que hizo Luis Alberto Sánchez.

Es necesario decir algo. Durante la batalla de Arica Elmore había sido hecho prisionero el 29 de mayo de 1880. El capitán de navío chileno Pedro Lagos declaro al Eco de Tacna en junio de 1880, refiriéndose a Elmore: “Me es verdaderamente doloroso que se imputen a dicho señor actos de infidencia a su patria y de cobardía. Me hago un deber declarar aquí que el ingeniero mencionado fue parco y categórico en sus respuestas, prohibiéndome mi propia delicadeza y el respeto a la dignidad ajena, arrastrar al señor Elmore a revelaciones, que cualquiera que hubieran sido, en nada hubieran cambiado mi modo de proceder en todo lo que se relaciona con el asalto de Arica (Paz Soldán, MF; 1883).

Nota DEL EDITOR

Se espera que la lectura de este artículo sirva para la meditación y, de estar interesado en hecho alguno de lo relatado, sea el germen de una búsqueda posterior. 